\title{
O clássico e o regional em José Américo de Almeida
}

\author{
ELIZABETH MAIA DA NÓBREGA \\ Universidade Federal da Paraíba
}

RESUMO: Nosso intento é assinalar elementos da cultura clássica presentes em A Bagaceira, obra de José Américo de Almeida, assim como identificar o clássico que aí se plasma na confluência do regional com o universal.

PALAVRAS-CHAVE: Clássico; forma; conteúdo; bagaceira; regional.

O romance, objeto de análise, foi aclamado, por significativa parte da crítica literária,' como marco do regionalismo brasileiro. Esse distintivo lhe foi atribuído porque seu autor rompe com a tradição e inaugura o moderno romance regionalista. Tal ruptura deve-se à mudança do enfoque temático, em que a miséria endêmica do Nordeste não é avaliada unicamente a partir dos dados fisiográficos, mas a partir da análise social. ${ }^{2}$ Aliás, antes de $A$ Bagaceira, José Américo já realizara um expressivo trabalho de caráter sociológico, $A P a-$ raíba e seus problemas, revelando seu então interesse por questões sociais.

Publicada em 1928, dois anos após o "Manifesto Regionalista do Nordeste" (1926), A Bagaceira antecipa-se às obras do mesmo gênero de Amando Fontes, Rachel de Queiroz, José Lins do Rego, Graciliano Ramos, Jorge Amado entre outros. ${ }^{3} \mathrm{O}$ que há de comum no trabalho desses autores, além do gênero, é claro, é o fato de seus escritos permanecerem atuantes, questionadores, pois, como observa Cavalcanti Proença (1978, p. 109) eles se oferecem ao leitor qual obra aberta.

1 Cf. a esse respeito Eduardo Potella, Fundamento da investigação literária, p. 70, assim como Ângela Maria Bezerra de Castro, Re-leitura de A Bagaceira; uma aprendizagem de desaprender, pp. 59-68.

2 Para melhor compreensão desse fato é de fundamental importância a leitura do trabalho acima citado de Ângela Maria Bezerra de Castro.

3 Desde 1927 a produção poética no Nordeste já se pautava por essa expressão moderna, como é o caso de Catimbó, de Ascenso Ferreira, Poemas, de Jorge de Lima, ou Livro de poemas, de Jorge Fernandes. Cf. a esse respeito o Prefácio da edição crítica de $A$ Bagaceira, de Milton Paiva, Elisalva de Fátima Madruga e Neroaldo Pontes de Azevedo (Almeida, 1999). 


\section{Qual a trama de A Bagaceira?}

O romance conta a vida no engenho Marzagão, cujo cotidiano é interrompido pela chegada inesperada de retirantes sertanejos. Dagoberto Marçau é um antiquado e inescrupuloso senhor de engenho, cujo desmando se prolonga na figura apendicular de Manuel Broca, seu feitor.Lúcio, o filho-herdeiro, é estudante de Direito e encarna os ideais progressistas. Já por essa razão é conflituosa sua relação com o pai. Mas trata-se de um conflito em estado latente, posto que até o final do romance jamais enfrenta o desmedido comportamento paterno. Aliás, a personalidade ambivalente de Lúcio está inicialmente expressa no título que identifica o segundo capítulo do livro: "Duas almas num só corpo" (Almeida, 1989 , p. 42). Efetivamente, aqui, tanto presenciamos o pedido pungente de Lúcio, que, atordoado com a atitude do pai, no caso Xiname, lhe diz para não amassar "seu pão com o suor dos pobres" (Almeida, 1989, p. 43), como somos surpreendidos com a descrição de um outro Lúcio, capaz de cometer com requinte as maiores crueldades contra os animais (Almeida, 1989, p. 44). Mas este último estava guardado nas lembranças da infância. O que se dava a conhecer era um jovem tímido, dotado de princípios reformadores que se concretizarão somente após a morte de Dagoberto. Sua oposição ao pai não passava "de uma rebeldia inativa, pois preferia retrair-se da luta pela vida, como quem estaciona à margem do caminho para dar passagem a um desconhecido" (Almeida, 1989, p. 47). Tal pusilanimidade se manifesta também na ocasião em que toma conhecimento que o pai desonrara Soledade, a mulher por quem estava apaixonado. Cambaleante, Lúcio pronuncia: "devo desaparecer daqui para que não fique interposto nesse amor..." (Almeida, 1989, p. 139).

Soledade é a sertaneja que chega ao engenho Marzagão junto com a última leva dos retirantes. Ela é sem dúvida a personagem mais marcante desse romance cujas linhas-deforça são a seca, o amor, a honra sertaneja, a vida promíscua nos engenhos, o contraste entre o Brejo e o Sertão. Ouso mesmo dizer que a trajetória da vida de Soledade emoldura o tema central do livro: o ambiente deletério da bagaceira.

Bagaceira é o nome que indica o lugar no engenho de açúcar onde se coloca o bagaço da cana. O termo designa também coisa sem valor e assume a conotação moral de ralé, plebe. Na estrutura político-fundiária em que nasceram os engenhos, a relação patrão/ empregado atingiu o paroxismo da desigualdade, num período histórico em que teoricamente há muito já havia ocorrido a abolição da escravatura. Por isso era gritante a degradação dos valores morais, a coisificação do homem nesse meio social. $O$ romancista mostra que "este ambiente corrosivo destruirá, dos sertanejos, os seus maiores bens, a honra e a liberdade. Dos brejeiros, quase nada. Porque estes já não tinham o que perder". ${ }^{4}$

Resumidamente esta é a trama de A Bagaceira. Quais seriam os elementos clássicos que integram a composição da obra? Antes de responder a essa questão vejamos em que consiste o clássico.

Hegel (1944, Tome II, p. 143ss.) trata desse tema analisando a relação forma/conteúdo do objeto estético. Para o filósofo as formas de arte não podem ser de uma variedade acidental. Ao contrário, a cada conteúdo deve corresponder uma forma que seja digna dele.

4 Como nota a percuciente re-leitura de Ângela Maria Bezerra de Castro, (Castro, 1987, p. 27). 
No campo da arte, o êxito da idéia enquanto conteúdo engendra ao mesmo tempo o êxito da forma. E inversamente o inacabado da forma revela ao mesmo tempo o inacabado da idéia, posto que é esta que confere à manifestação externa, mediante a qual se realiza, uma significação interna. "Não se trata aqui de uma obra frustrada", nos adverte Hegel. Mas, para cada conteúdo, a forma, sob a qual a idéia se realiza, corresponde àquilo que deve exprimir, e o inacabado ou a perfeição dependem do grau de verdade implícito na idéia. Pois o conteúdo deve ser verdadeiro e concreto antes de encontrar a forma que lhe convém. Sob essa ótica, Hegel distingue três formas principais de arte: a simbólica, a clássica e a romântica.

A arte simbólica é aquela que não consegue fundir o significado interno com a forma externa, a arte clássica realiza essa união representando a individualidade substancial para nossos sentidos, a arte romântica se mostra completamente indiferente à forma, posto que se dirige fundamentalmente ao nosso espírito.

O símbolo é o quilômetro zero da arte, tanto do ponto de vista conceitual quanto histórico. $\mathrm{Na}$ arte simbólica não há adequação entre sentido interno e expressão exterior. Do ponto de vista do conceito, o símbolo possui sempre um duplo sentido. Ele se apresenta primeiro enquanto imagem dotada de existência imediata; segundo, enquanto representação abstrata. Primeiro, como significação própria, e segundo, como significação figurada. A imagem de um leão pode ser apenas um leão e pode querer representar a noção abstrata de força, como nos ensina Hegel.

Por natureza a arte clássica não tem nada de simbólico, ou seja, só exprime seu conteúdo, porque encontrou a forma para fazê-lo. $\mathrm{O}$ que ainda confere um duplo sentido às obras de arte clássicas é o uso de figuras mitológicas da Antiguidade, diante das quais nos perguntamos sempre se devemos compreendê-las apenas como se apresentam exteriormente, ou se esse exterior contém um sentido que lhe ultrapassa. Mas é verdade que a arte clássica surge pela mediação da arte simbólica.

Quais são as características gerais da arte clássica segundo Hegel?

Antes de tudo convém elucidar as condições histórico-político-religiosas que viabilizaram o nascimento daquilo que o filósofo compreende como arte clássica.

Historicamente esta surge quando a ação do homem não representa mais uma resposta exclusiva às necessidades e pressões da natureza, mas circunstancia-se "num estado fundado na justiça, na propriedade, nas leis e na organização da vida política" (Hegel, 1944, Tome II, p. 186.) Além disso, no plano religioso, a arte clássica surge quando as potências naturais são substituídas por deuses individuais e espirituais. Ou seja, assim como a arte simbólica está associada ao mundo privado e às religiões telúricas sem conteúdo moral ou espiritual, a arte clássica está associada ao lado universal da existência humana, à vida coletiva e pública e às religiões politeístas. São, portanto, os elementos naturais que a arte clássica elimina tanto de seu conteúdo quanto de sua forma.

Por conseguinte, não é difícil avaliar por que, no mundo antigo, a Grécia se constitui no berço do ideal e da beleza clássicos. É para ela que olhamos, quando identificamos o quadro histórico-religioso que acabamos de mencionar. E se nos referirmos também às circunstâncias políticas, é preciso lembrar que o grego conheceu o meio termo entre a liber- 
dade subjetiva e a consciência moral. Ao contrário dos orientais que não conheceram o significado de indivíduo, os gregos, ao mesmo tempo em que se submetiam às leis do Estado, permaneciam independentes e autônnomos em relação ao mesmo. De modo que, na vida cotidiana, exerciam equilibradamente os princípios da moral universal e das liberdades individuais. Ou seja, o elemento político não era extemporâneo à moral subjetiva. Daí a importância do político para os gregos, os quais acreditavam que a concretização dos fins comuns engendrava a afirmação de suas liberdades individuais. Ora, é o espírito dessa harmonia que observamos em todos os empreendimentos realizados pelo gênio grego.

Resumidamente, estas são as condições histórico-político-religiosas que permitiram a eclosão da arte clássica. Podemos agora situar a origem de seus elementos constitutivos.

Sem dúvida a principal matéria prima da arte clássica são as religiões naturais e a mitologia que daí derivou. Fazem parte também dessa argamassa alguns componentes históricos, na medida em que várias narrativas, inclusive as referentes aos deuses, foram claramente inspiradas no cotidiano do homem grego, em indivíduos históricos, heróis, grupos étnicos antigos, fenômenos e acidentes naturais, combates, guerras etc. Da hábil combinação desses fatores nasceu a arte clássica.

Vejamos, portanto, em que consistem suas principais características.

A independência da significação neste gênero artístico exige que este encontre sua forma no elemento natural. Ou seja, o exterior do objeto estético deve representar seu interior, mais precisamente deve constituir um aspecto do interior. Graças a essa relação de reciprocidade entre interior e exterior, o lado natural e exterior assume uma significação em si, ao invés de arbitrariamente significar algo diferente de sua manifestação externa, como ocorre, por exemplo, na arte simbólica. ${ }^{5}$ É justamente nessa espécie de unidade, em outras palavras, na adequação da forma ao conteúdo, que se funda o conceito de arte clássica.

E, posto que é absolutamente indispensável tornar o conteúdo transparente através da forma, a figura humana constitui a expressão perfeita do ideal clássico, pois somente nesta forma o espírito pode receber adequadamente uma existência sensível e natural.

A arte clássica supõe, obviamente, um nível já bastante elevado de expertise técnica, de modo que seu artista, dotado de uma idéia clara sobre aquilo que quer significar e dominando tecnicamente a realização plástica de tal conteúdo, concebe obras em que a forma não atua hegemonicamente sobre o conteúdo, e vice-versa.

Mesmo porque, em conformidade com o que acabamos de dizer, o ideal clássico exige que os objetos estéticos sejam regulares, simétricos, regidos por leis e dotados de harmonia. Por essa razão, a expressão plástica desse ideal é, segundo Hegel, a escultura grega.

Mas não desconhecemos que o filósofo (Hegel, 1944, Tome II, p. 158) considera como clássica, grosso modo, toda obra de arte perfeita, qualquer que seja, aliás seu caráter simbólico ou romântico. E a perfeição reside na marca que o espírito individual imprimiu

5 As representações da arte simbólica são enigmas que devemos desvendar, enquanto que as representações da arte clássica não pedem para ser decifradas, pois seu conteúdo já está claramente desenvolvido. 
ao conteúdo e no modo como este se externou formalmente. É nessa relação adequada entre forma e conteúdo que reside a perfeição.

Eis muito resumidamente o caráter geral da arte clássica.

Do texto hegeliano retomado e modificado aqui e ali por vários autores "nasceu a idéia convencional do classicismo", observa Abbagnano (1962, p. 135), "como medida, equilíbrio, serenidade, harmonia". Doravante não caberá exclusivamente à escultura representar a arte clássica, como preferia Hegel. Ter-se-á como clássica a arte "representativa de um mundo melhor, normativa, de seres eticamente superiores" (Hauser, Tomo I, 1982, p. 123). O termo kalokagathia, tributário da primitiva ética aristocrática (Jaeger, 1989, p. 24), que designa o belo enquanto honra, altivez e magnanimidade, sintetiza o ideal do espírito clássico. Neste sentido a arte clássica é ao mesmo tempo intérprete e criadora da tradição. Por conseguinte, o agente da cultura clássica é, por assim dizer, o guardião dos valores elevados. Convém, no entanto, lembrar que apesar de toda similitude é enorme a diferença entre o classicismo antigo e o classicismo moderno. De todos os elementos da arte clássica o mais sensível ao tempo é sem dúvida o ideal de kalokagathia, porque se enraíza nos princípios morais da nobreza cavalheiresca, e portanto, se inscreve num quadro sócio-político que a história deixou para trás. ${ }^{6}$

Na literatura, clássica é a obra que, em função da adequação forma/conteúdo, resiste ao tempo e se impõe como modelo de linguagem, no tratamento de temas universais.

Cabe agora a pergunta: entre os componentes que objetivam a obra A Bagaceira que elementos reputaríamos de clássicos?

Vejamos se ali o conteúdo e a forma relacionam-se adequadamente. Isso implica em dirigir nosso esforço interpretativo para identificar os vínculos entre a realidade sócio-político-cultural e a forma narrativa ficcional.

Ao lado da seca, a bagaceira representa a danação dos personagens do romance. Estão imbricadas neste epicentro questões de ordem geográfica, política, econômica e cultural, como os freqüentes e por demais prolongados estios sertanejos, a estrutura fundiária feudal do brejo e a inconseqüente política coronelista dos senhores de engenho. Os aspectos culturais estão expressos, sobretudo, nas relações antitéticas que se estabelecem entre brejeiros e sertanejos.

O romancista encontra, sem dúvida, sua matéria prima no cotidiano de Areia, sua cidade natal e região de engenhos de açúcar; na prática política e nos acontecimentos que antecederam a Revolução de 1930, em que conservadores e liberais disputaram a hegemonia política do país; e, sobretudo, inspira-se na natureza humana e nos mitos de honra, solidariedade, liberdade, valentia, amor à gleba, todos idealizadores do homem sertanejo.

Como a linguagem dá forma a tal conteúdo?

É extremamente significativo o aforismo inicial do Antes que me falem (Almeida, 1989, p. 35): "Há muitas formas de dizer a verdade. Talvez a mais persuasiva seja a que tem a aparência de mentira", diz José Américo de Almeida parodiando o poeta da Teogonia. Ou

6 Nesse sentido, é esclarecedora a explicação de Arnold Hauser (Hauser, 19825, p. 466). 
seja, o escritor elege a ficção, ao invés do ensaio, porque acredita que esta forma narrativa confere maior verossimilhança a seu discurso. Interessa-lhe, sobretudo, mostrar que a seca não é a única e nem mesmo a principal causa das desigualdades sociais existentes no Nordeste, sem assumir, todavia, o tom incisivo do ensaio científico, que adotara, por exemplo, em A Paraíba e seus problemas.

E para avaliarmos se aqui a forma ficcional conferiu transparência à verdade implícita no tecido narrativo, é preciso que saibamos distinguir os vários planos linguísticos do romance.

Tristão de Athayde já havia indicado um duplo registro na linguagem de A Bagaceira: um culto, outro bárbaro. Em seu Estudo introdutório, M. Cavalcanti Proença (1978, p. 4689) também aponta para a coexistência de duas linguagens: a do autor, que classifica de culta e a dos personagens, as quais situa em planos distintos. Lúcio, por exemplo, expressase no mesmo estilo do autor, ao passo que Soledade é "simples e direta" (Proença, 1978, p. 82). Distinta é ainda a linguagem dos sertanejos Pirunga e Valentim, que se afirma no texto de modo "vigoroso, conciso, adornado, apenas, de vocábulos e imagens regionais" (Proença, 1978, loc.cit). E finalmente em oposição à linguagem do escritor constrói-se a fala dos cabras do eito, rica em termos regionais e frases feitas populares.

São esses diferentes planos da linguagem que, segundo M. Cavalcanti Proença, emprestam à obra a feição de peça teatral. Há, inclusive, na construção dos diálogos o emprego do duplo sentido tão ao gosto do poeta trágico. Assim dialogou com Valentim o vaqueiro do sertão que passava na estrada.

- Eu não contava que o senhor tivesse descido...

O verbo descer aqui está indicando a direção do brejo. Mas o retirante pensando na desonra da filha responde (Proença, 1978, p. 87):

- Desci e... desci muito.

Em Sintaxe e semântica da expressão em A Bagaceira, José Brasileiro Vilanova (Apud Castro, 1987, p. 17) observa que a linguagem do texto almeidiano se desenvolve, na verdade, em três planos: a linguagem culta, erudita e às vezes teatral do autor: a regional, rica em plebeísmos e solecismos, dos moradores do Marzagão e a linguagem coloquial de Dagoberto, Lúcio e Soledade.

Luiz Tavares Junior (Apud Castro, 1987, p. 18), por sua vez, procura identificar a ideologia implícita nos diferentes registros linguísticos. Observa que o sertão fala a linguagem da liberdade, enquanto o brejo a da submissão. O autor e Lúcio, a maior parte do tempo, falam a linguagem da recriminação. A esses três aspectos ideológicos da linguagem Ângela Maria Bezerra de Castro argutamente acrescenta um quarto, sem o qual não poderia haver, como adverte a ensaísta, a linguagem da submissão. Trata-se da linguagem da dominação falada por Dagoberto e seu feitor Manuel Broca, e posteriormente por Lúcio como novo senhor do Marzagão.

Eis em resumo as principais análises da estrutura formal do romance. E no dizer de M. Cavalcanti Proença, "o autor usa com a mesma naturalidade tanto a linguagem regional quanto a linguagem culta, pois é afeito ao trato íntimo de ambas" (1978, p. 83). 
À medida que o romance avança e erige os valores éticos do sertão em contraposição à promiscuidade do brejo, o regional assume, portanto, a categoria universal, posto que a ética é universal.

Finalmente, para concluirmos que aqui a forma ficcional ajusta-se ao conteúdo, recordemos as palavras de Rachel de Queiroz $(1989$, p. 107) que atribui "força e autoridade" de estadista aos aspectos sociais presentes em A Bagaceira.

Afinal, a obra que inaugura o Moderno Regionalismo Brasileiro permanece emblemática, como o comprova incontestavelmente sua atual $34^{\mathrm{a}}$ edição.

\section{Referências bibliográficas}

ABBAGNANO, Nicola. Dicionário de Filosofia. Tradução coordenada e rev. Por Alfredo Bosi, com a colaboração de Maurice Cunio et alii. 2. ed.São Paulo: Mestre Jou. 1962, p. 980.

ALMEIDA, José Américo de. A Bagaceira.Introdução de M. Cavalcanti Proença. 34. ed. Rio de Janeiro: José Olympio. 2000, p. 153.

.A Bagaceira. Edição Crítica por Milton Paiva, Elisalva de Fátima Madruga e Neroaldo Pontes de Azevedo. Rio de Janeiro/João Pessoa: José Olympio/Fundação Casa de José Américo. 1989, p. 263.

.A Bagaceira. Com trabalhos de Alceu Amoroso Lima, Gilberto Freyre, Ivan Cavalcanti Proença, Juarez da Gama Batista, Leandro tocantins, M. Cavalcanti Proença, Odylo Costa Filho e Rachel de Queiróz. 15. ed. Rio de Janeiro/João Pessoa: José Olympio/ Secretaria de Educação de Governo do Estado da Paraíba. 1978, p. 269.

BARBOSA Filho, Hildeberto. A convivência crítica ; Ensaios sobre a produção literária da Paraíba. João Pessoa: Governo do Estado. 1985. 173.

CASTRO, Ângela Bezerra de. Re-leitura de A Bagaceira; (Uma aprendizagem de desaprender). Rio de Janeiro: José Olympio. 1987, p. 103.

FERRATER MORA, José. Dicionário de Filosofia. Tradução de Maria Stela Gonçalves, Adail U. Sobral, Marcos Bagno, Nicolás Nyimi Campanário. São Paulo: Loyola. 2000. Tomos I, II, III e IV.

HAUSER, Arnold. Historia Social da Literatura e da Arte. Trad. de Walter H. Geenen. 4. ed. São Paulo: Mestre Jou. 1982. t. I e II.

HEGEL, G.W.F. Esthétique. Traduit par S. Jankélévitch et alii. Paris: Aubier, Éditions Montaigne. 1944. Col. Philosophie de l'Esprit. t. 1, II, III, IV.

JAEGER, Werner. Paideia ; A formação do homem grego. Tradução de Artur M. Parreira. 2. ed. São Paulo: Martins Fontes. 1989, p. 966.

LEITE, Norma Lins. Bibliografia comentada de José Américo de Almeida ; Obras do Autor e sobre o Autor. 1921-1996. João Pessoa : Editora Universitária/Fundação Casa de José Américo. 1998, v. I, p. 188. 
SANTIAGO, Silviano. Uma litertura nos trópicos. São Paulo: Editora Perspectiva. 1968. Col. Debates, p. 212.

SANTOS, Idelette Fonseca dos.(Org.). A Literatura na Paraíba; Ontem \& Hoje. João Pessoa : Fundação Casa José Américo. 1989, p. 192.

RABELLO, Adylla Rocha. Exposição comemorativa dos sessenta anos de A Bagaceira. João Pessoa : Fundação Casa de José Américo. 1998, p. 45.

. José Américo de Almeida nos bastidores. Brasília: Senado Federal. 1994. Dissertação para o Curso de Mestrado em Letras/UFPB, p. 193.

NOBREGA, Elizabeth Maia da. Le classique et le régional chez José Américo de Almeida. Classica, São Paulo, 15/16, p. 277-284, 2002/2003

RÉSUMÉ: Le but de ce travail est de souligner des éléments de la culture classique présents dans l'oeuvre de José Américo de Almeida $A$ Bagaceira, ainsi que d'identifier le classique qui s'y produit dans la confluence du régional avec l'universel.

MOTS-CLÉS: classique, forme ; contenu ; bagaceira, régional. 